\title{
ORBIT COMPENSATION FOR THE TIME-VARYING ELLIPTICALLY POLARIZED WIGGLER WITH SWITCHING FREQUENCY AT $100 \mathrm{HZ}$
}

\author{
O. Singh and S. Krinsky \\ NSLS, Brookhaven National Laboratory \\ CONF-970503-7.3
}

Abstract

In October 1996, the elliptically polarized wiggler, installed in the $\mathrm{X} 13$ straight section of the NSLS X- ray ring, was commissioned at an operating frequency of $100 \mathrm{hz}$. This wiggler generates circularly polarized photons in the energy range of 0.1 to $10 \mathrm{keV}$ with $\mathrm{AC}$ modulation of polarization helicity. The vertical magnetic field is produced by a hybrid permanent magnet structure, and the horizontal magnetic field is generated by an electromagnet capable of switching at frequencies up to $100 \mathrm{hz}$. Here, we discuss the compensation of the residual vertical and horizontal orbit motion utilizing a time-domain algorithm employing a function generator to drive trim coils at the wiggler ends, and the wideband high precision orbit mesurement system of the X-ray ring. The residual orbit motion has been reduced to a level below 1 micron, and the device has been run in regular operations with no negative effect on other users.

\section{INTRODUCTION}

The time-varying elliptically polarized wiggler $[1,2,3]$ was installed in the X13 straight section of the NSLS X-ray ring in December 1994. This device produces variable polarized $x$-rays, with the right- /eft- handedness of polarization switchable at up to $100 \mathrm{~Hz}$, making possible the use of gating or lock-in amplifier techniques to detect the very weak signatures of circular dichroism and other effects associated with right- vs. left- handedness of some physical and biological systems. The DC vertical magnetic field is produced by a hybrid permanent magnet wiggler, and the time-varying horizontal magnetic field is generated by an $\mathrm{AC}$ electromagnet wiggler. Critical to the successful operation of the $\mathrm{AC}$ electromagnet wiggler is the maintenance of the high degree of orbit stability required by the many experimental beamlines on the X-ray ring. Orbit compensation of the time-varying elliptically polarized wiggler operating at $2 \mathrm{~Hz}$ was described in ref. 4 . Here, we discuss the compensation of the residual orbit motion for $100 \mathrm{~Hz}$ operation, utilizing a time-domain algorithm employing a function generator to drive the trim coils at the wiggler ends.

\section{COMPENSATION METHOD}

Our approach for $100 \mathrm{hz}$ compensation consists of several steps: 1) measure orbit distortion in time-domain at two pick-up electrodes (pues) with electromagnet switching at $100 \mathrm{hz}, 2$ ) process these waveforms to remove offsets and add gains, 3) load processed waveforms into function generators which produce correction signals in synchronism to switching frequency, 4) apply correction signals to end trims and observe the frequency spectrum of residual distortion at the switching frequency and its harmonics. Fig. 1 shows the block diagram for the dynamic compensation system

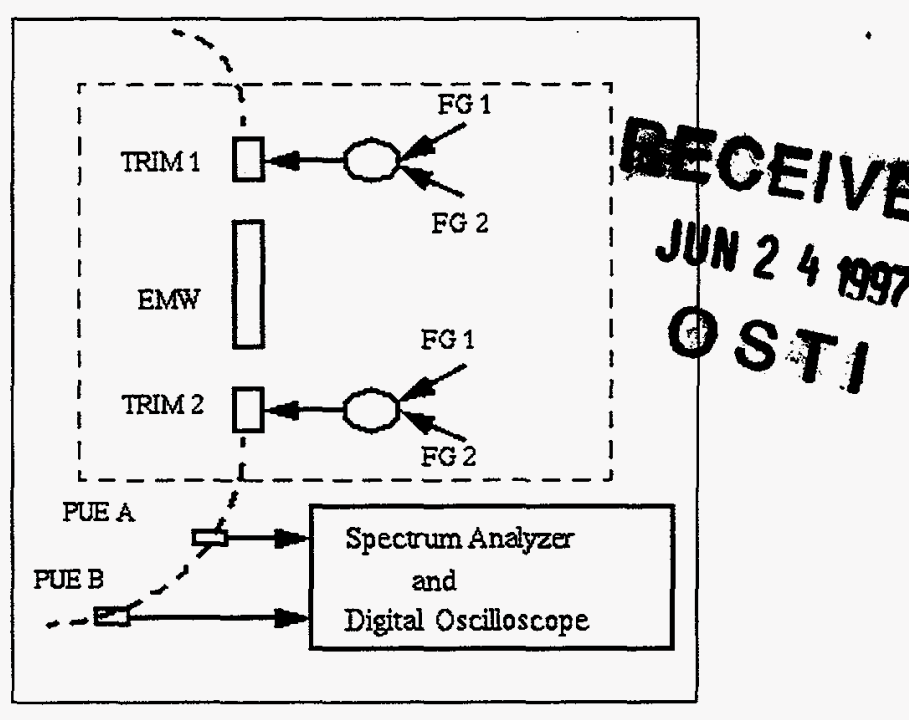

Figure 1: Dynamic Compensation System.

\section{I Time-domain orbit distortion measurement}

A fast digital oscilloscope (LeCroy 9354) is used to measure orbit distortion. This oscilloscope is set up to sample at $1 \mathrm{Mhz}$ and to collect 10,000 data points for every frame of $10 \mathrm{msec}$. Each frame's data is averaged point-to-point over several hundred frames. The averaging is critical to obtain an accurate time-domain orbit distortion because it removes ambient background motion. The dominant spectral content of the ambient orbit motion lies in the frequency range of $8 \mathrm{hz}$ to $60 \mathrm{hz}$ [4] and is cancelled by averaging. Figs. $2 b$ and $2 c$ show the uncompensated orbit distortion in the vertical and horizontal planes produced by the wiggler, in relationship to the driving wiggler current waveform shown in Fig. 2a. The level of distortions are 30 and 60 microns peak to peak in vertical and horizontal planes, respectively.

\subsection{Signal processing}

The measured average orbit distortion waveforms are transferred (off-line) to a PC based computer. The computer processes these waveforms to null for the offset in the orbit and to amplify the orbit waveform amplitude to provide sufficient correction trim signal level.

*Work supported by the Department of Energy, contracts DE-AC03-76SF00515 and DE-AC02-76CH00016 


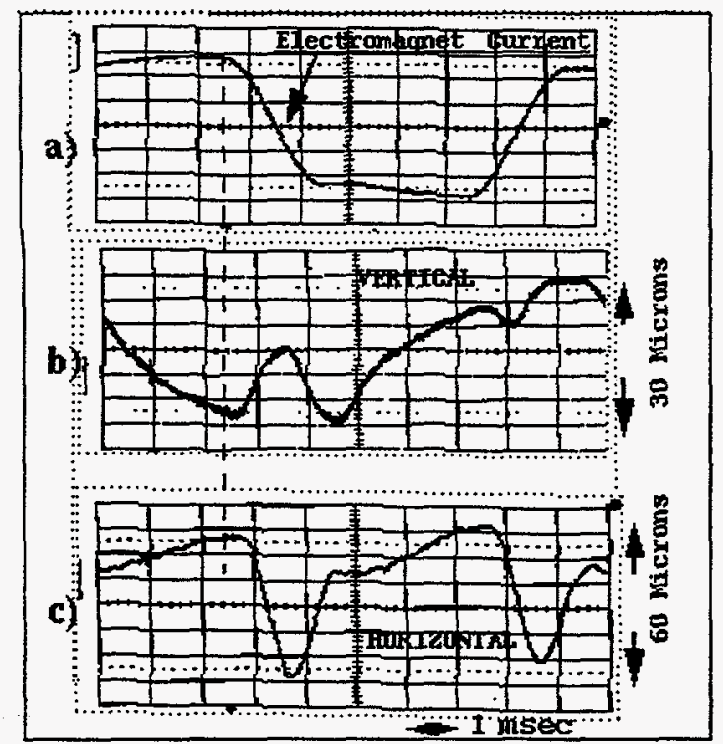

Figure 2: Waveforms with EPW (uncompensated) switching at $100 \mathrm{hz}$ with 400 amperes amplitude; (a) Current waveform (b) Vertical orbit distortion at pue $A$ and (c) Horizontal orbit distortion at pue $\mathrm{A}$.

\subsection{Function generators}

The output waveforms are loaded into function generators (Fluke 5150). These function generators provide $10 \mathrm{msec}$ long correction signals at every $100 \mathrm{hz}$ trigger. Fig. 3 shows a set-up diagram utilizing four function generators, two for each plane. Note that the phase of each waveform can be adjusted by varying $100 \mathrm{hz}$ trigger delays ( D1 to D4) to the function generators.

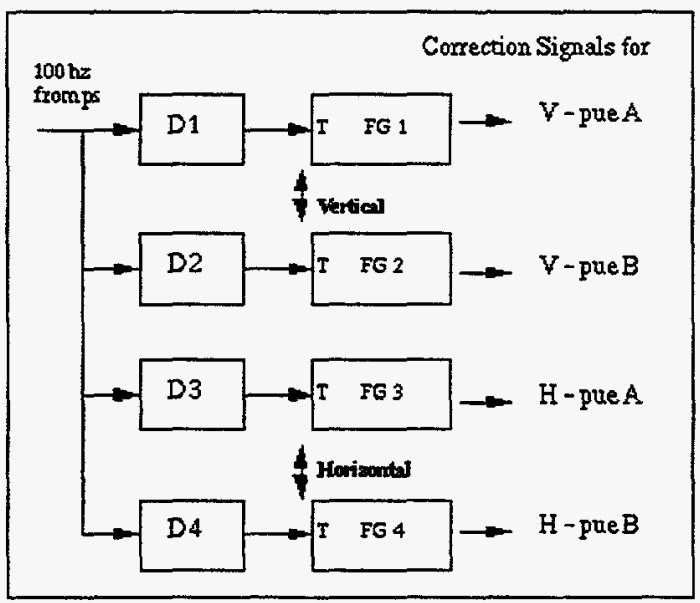

Figure 3: Function generators set-up with trigger delay units

\subsection{Compensation}

The spectrum analyzer was set to observe peaks at $100 \mathrm{hz}$ and harmonics. Each correction signal, which corresponds to a given pue, is applied to the end trims in a linear combination to correct orbit at that pue while leaving other pue unchanged. While minimizing $100 \mathrm{hz}$ line spectral amplitude, we noticed that harmonic line spectra amplitudes did not reduce. In fact, there was an increase in amplitude of some harmonics. This is due to the fact that the trim-to-pue response is not flat, see Fig. 4.

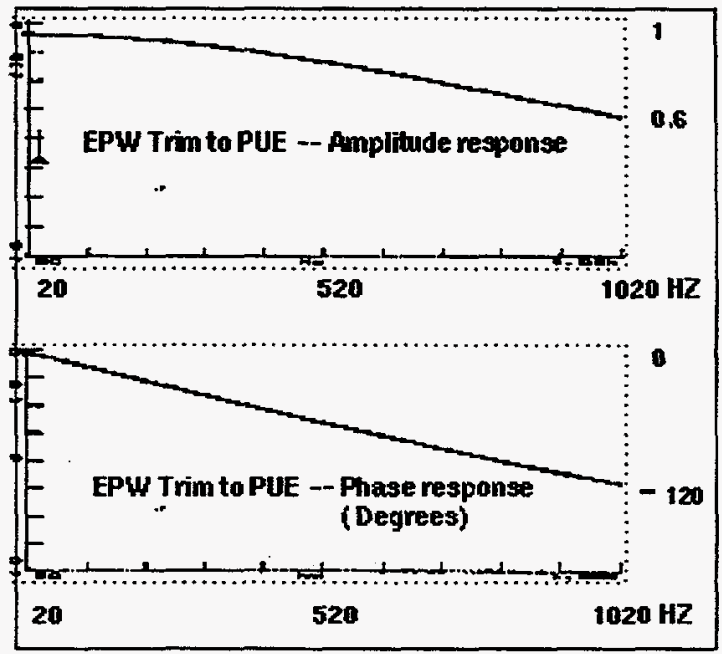

Figure 4: EPW trims to pues response.

For proper compensation, a new time-domain correction signal must be determined which takes into account the trim-to-pue response. In our approach, we determined this waveform by iteration, where each iteration minimizes the amplitude of only a few harmonics. Two iterations were sufficient to reduce the orbit distortion to a satisfactory level. The steps involved for compensation are discussed below. Let the first correction waveform be denoted by $F_{1}$, shown in Fig. 5a, which is a measured distortion waveform. During the 1st iteration, this waveform is loaded into the function generator and the line spectra's magnitude at 100 and $200 \mathrm{hz}$ are minimized by adjusting amplitude and phase of the correction waveform. The optimized correction amplitude and phase are denoted by $A_{1}$ and $P_{1}$. So, the optimized waveform is given by $\left(A_{1} F_{1}\right.$ with phase delay $P_{1}$ ).

With this correction, the residual orbit distortion $F_{2}$ is measured (Fig. 5b), and $F_{2}$ is now the new function for the 2nd iteration correction. In this iteration, the magnitude of the spectral lines at 300 to $600 \mathrm{hz}$ are minimized and the optimized correction amplitude is $A_{2}$ and phase delay is $P_{2}$. The two optimized correction waveforms are combined in the computer to generate the final correction wave form $\left(A_{1} F_{1}\right.$ with phase delay $\left.P_{1}\right)+\left(A_{2} F_{2}\right.$ with phase delay $P_{2}$ ). Fig. $5 \mathrm{c}$ shows the final residual orbit. No further iteration was necessary. The orbit distortion in frequency domain without compensation is shown in Fig. 6a; the distortion after 1 st iteration is shown in Fig. $6 \mathrm{~b}$ (note 100 and $200 \mathrm{hz}$ peaks are reduced); and the distortion after 2 nd iteration is shown in Fig. 6c (note all peaks are minimized). In time-domain, as shown in Fig 5, the vertical orbit distortion was reduced from 30 to 4 microns peak to peak (compare Figs. 5a to 5c). In frequency domain, $100 \mathrm{hz}$ ver- 


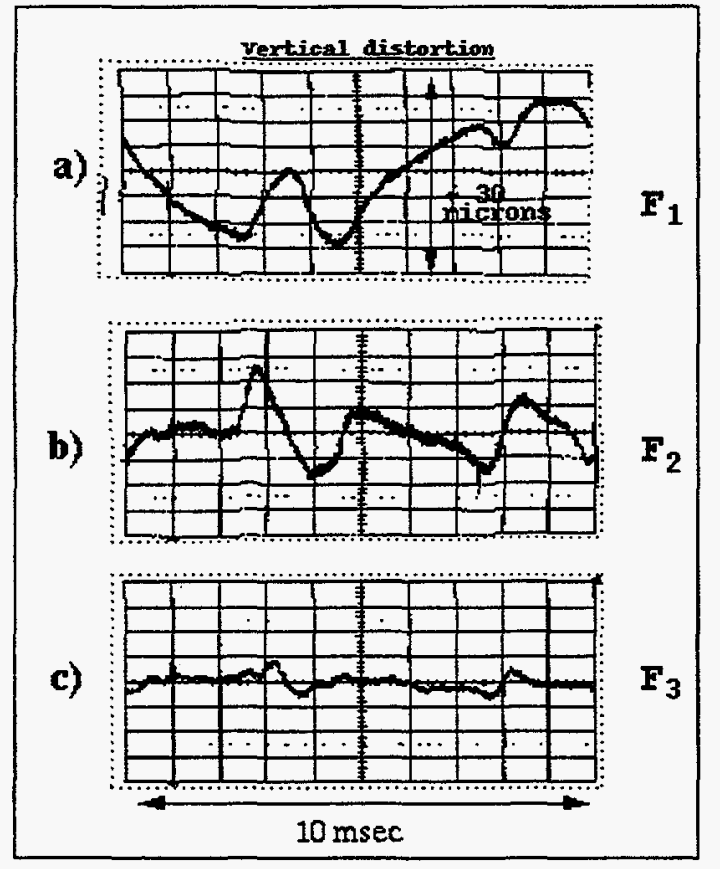

Figure 5: Time domain vertical orbit distortion when EPW switching at $100 \mathrm{hz}$ : (a) no compensation (b) 1st iteration compensation and (c) 1 st and 2 nd iteration compensations. tical distortion is reduced from 18 to 1.2 microns peak to peak (compare Figs. $6 \mathrm{a}$ and $6 \mathrm{c}$ ). Compensation results for horizontal plane are shown in Figs. $7 \mathrm{a}$ and $7 \mathrm{~b}$ without and with compensation, respectively.

\section{ACKNOWLEDGEMENTS}

We would like to acknowledge work done by $H$. Link and G. Frisbie for evaluating and programming efforts in the function generators. We would also like to acknowledge the collaboration with P.M. Ivanov and E.A. Medvedko in the early stages of this work. Work performed under the auspices of the U.S. Department of energy undercontract DE-AC02-76CH00016.

\section{REFERENCES}

[1] A. Friedman, S. Krinsky, and E. Blum, " Polarized Wiggler for NSLS X-Ray Ring: Design Consideration," Informal Report BNL - 47317, March, 1992.

[2] A. Freidman, X. Zhang, S. Krinsky, E. Blum and K. Halbach, "Polarized Wiggler for NSLS X-ray Ring", Proc. 1993 Part. Accel. Conf., Washington, D.C., May, 1993, p. 1599.

[3] E. Gluskin, D. Frachon, P.M. Ivanov, J. Maines, E. A. Medvedko, E. Trakhtenberg, L. R. Turner, I. Vasserman, G. I. Erg, Yu. A. Evtushenko, N. G. Gavrilov, G.N. Kulipanov, A. S. Medvedko, S. P. Petrov, N. A. Vinokurov, A. Friedman, S. Krinsky, G. Rakowsky, O. Singh, " The Elliptical Multipole Wiggler Project," Proc. 1995 Part. Accel. Conf., Dallas, Tx, May, 1995.

[4] O. Singh, S. Krinsky, P.M. Ivanov, and E. A. Medvedko," Orbit Compensation for the Time Varying Elliptically Polarized wiggler," Rev. Sci. Instrum. 67(9), September 1996.

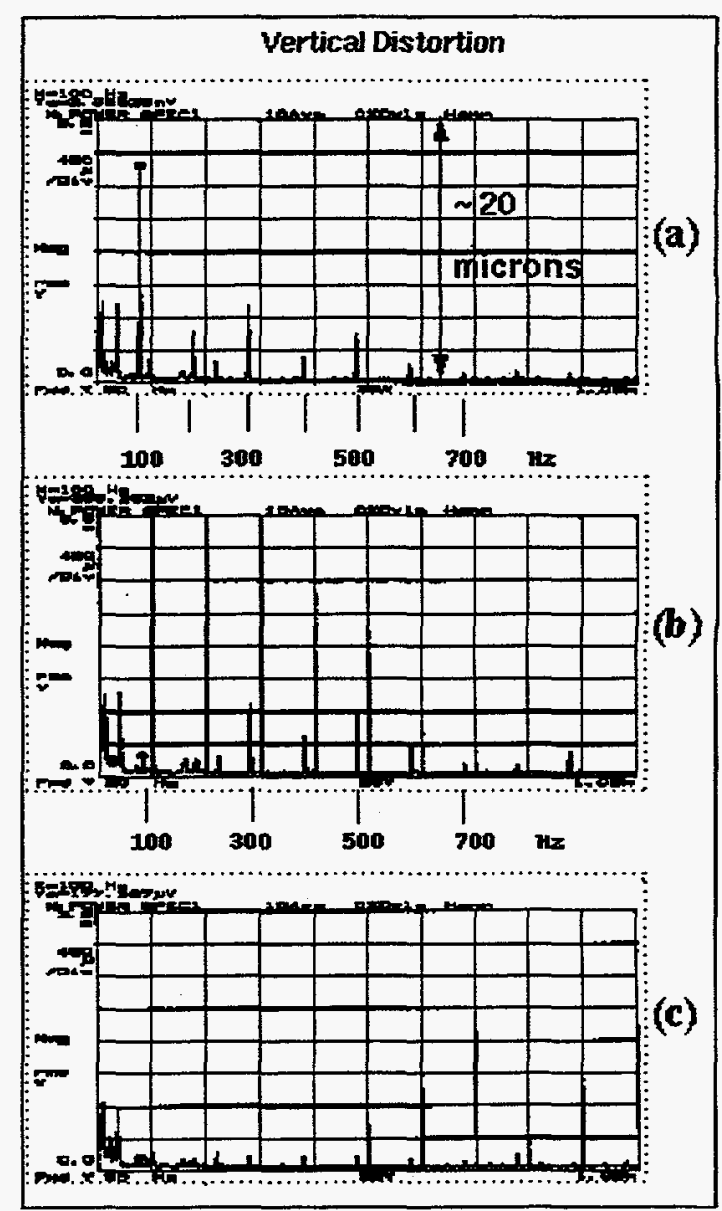

Figure 6: Fourier spectrum of vertical orbit when EPW switching at $100 \mathrm{hz}$ : (a) no compensation (b) 1st iteration compensation and (c) 1 st and 2 nd iteration compensations.

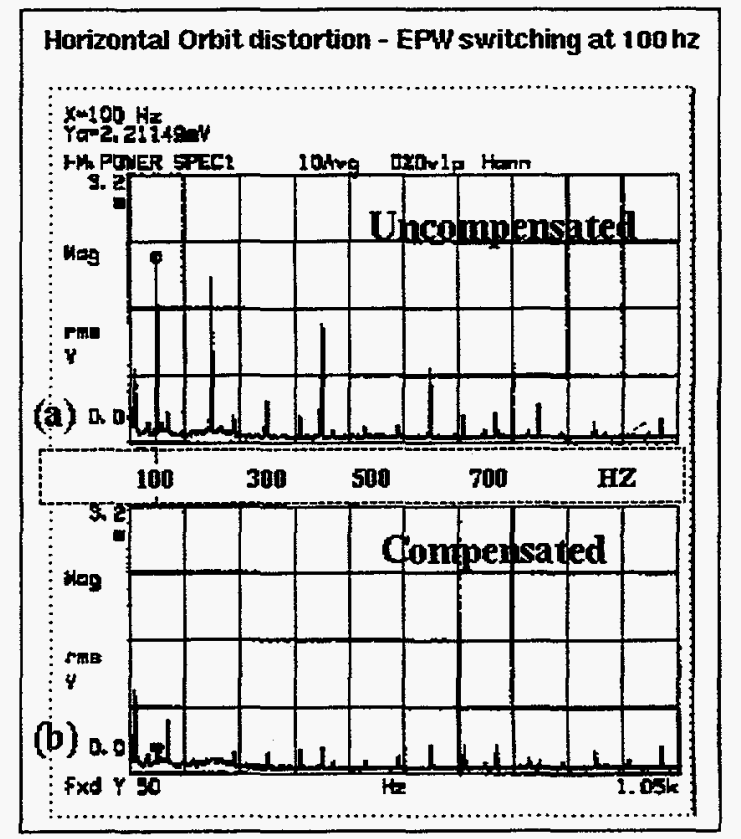

Figure 7: Fourier spectrum of horizontal orbit when EPW switching at $100 \mathrm{hz}$ : (a) no compensation and (b) with full compensation. 


\section{DISCLAIMER}

This report was prepared as an account of work sponsored by an agency of the United States Government. Neither the United States Government nor any agency thereof, nor any of their employees, makes any warranty, express or implied, or assumes any legal liability or responsibility for the accuracy, completeness, or usefulness of any information, apparatus, product, or process disclosed, or represents that its use would not infringe privately owned rights. Reference herein to any specific commercial product, process, or service by trade name, trademark, manufacturer, or otherwise does not necessarily constitute or imply its endorsement, recommendation, or favoring by the United States Government or any agency thereof. The views and opinions of authors expressed herein do not necessarily state or reflect those of the United States Government or any agency thereof. 


\section{DISCLAMIIR}

Portions of this document may be illegible in electronic image produets. Images are produced from the best available original document. 